\title{
Trajetória às Cegas
}

Lucas Salgado ${ }^{1}$

\section{Blind Path}

1 Nascido em Niterói. Reside no Rio de Janeiro.

Graduando em Artes Visuais pela Universidade do Estado do Rio de Janeiro, tem sua primeira formação em Engenharia Mecânica.

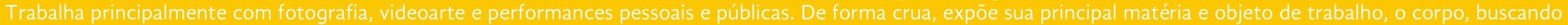

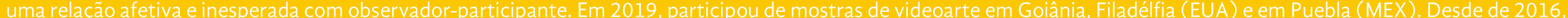

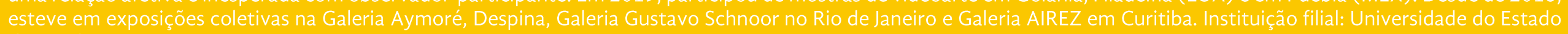
do Rio de Janeiro 
10 de novembro de 2018

Na véspera de seu aniversário, o artista é conduzido vendado por passantes desconhecidos, caminhando de sua primeira casa ao local de seu nascimento.

Inicialmente, fica-se imóvel até que alguém inicie uma comunicação. Caso essa pessoa ofereça ajuda, é solicitada a condução até outro ponto onde novamente se mantém estático até que outra conversa se inicie. Durante o caminho a seguinte frase é repetida:

"Estou indo para o lugar onde nasci. Amanhã irei nascer".

O trajeto completa 2,1 km e cerca de 1 hora e 30 minutos entre o bairro de Icaraí e o Hospital Santa Cruz no Centro de Niterói, num caminho reverso ao feito em seu primeiro dia de vida. 


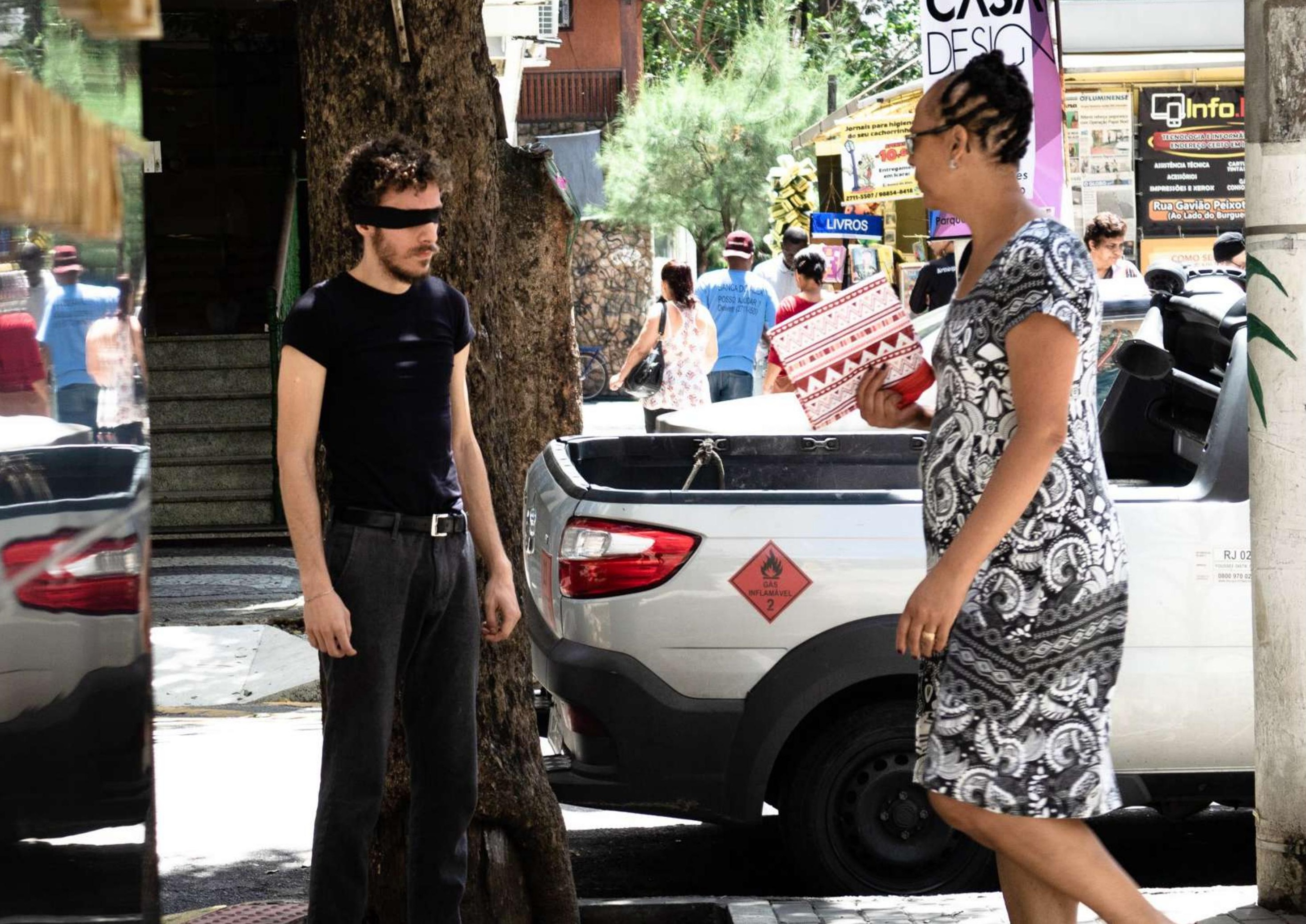




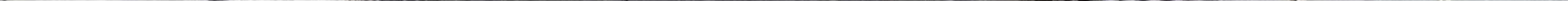




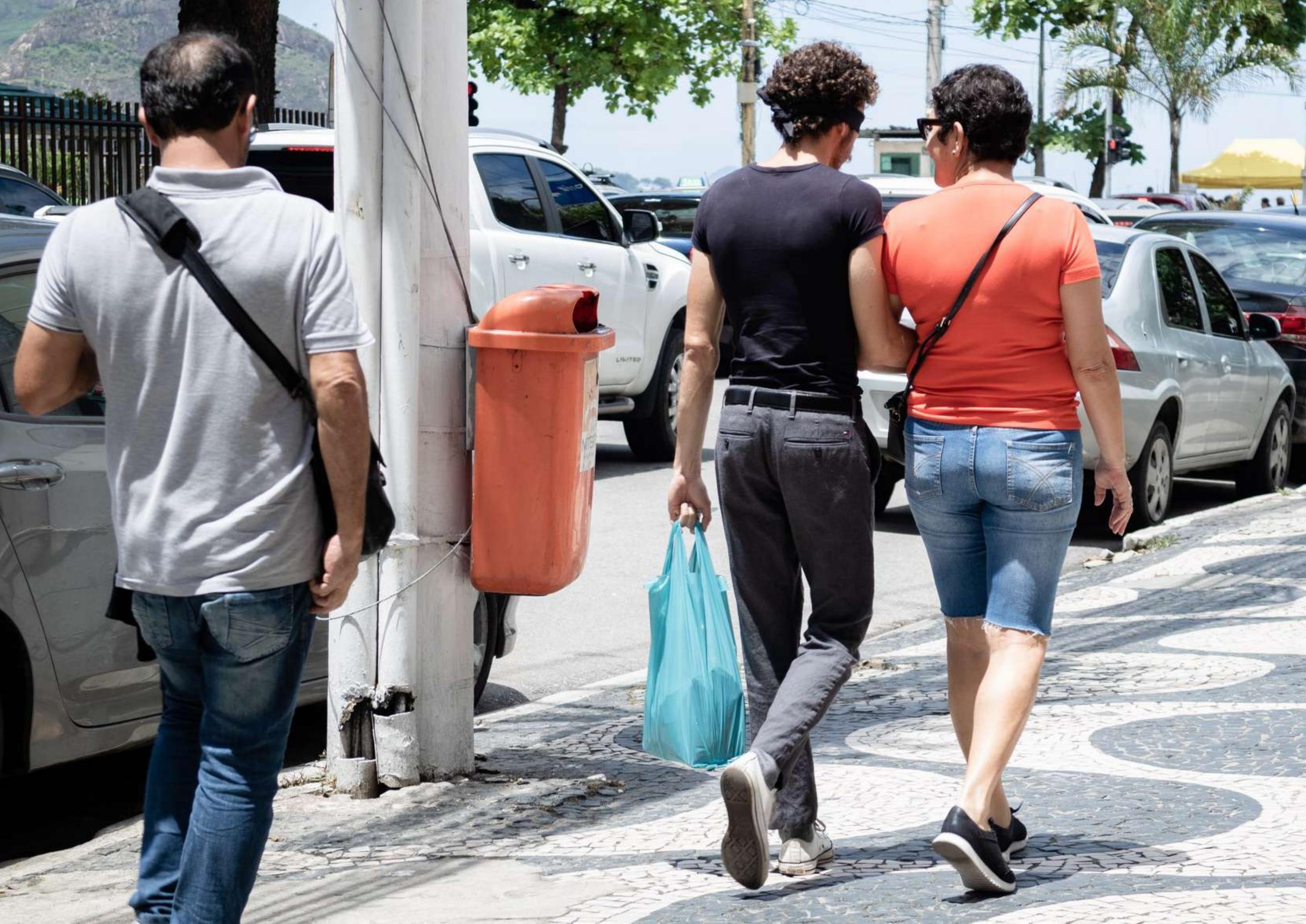




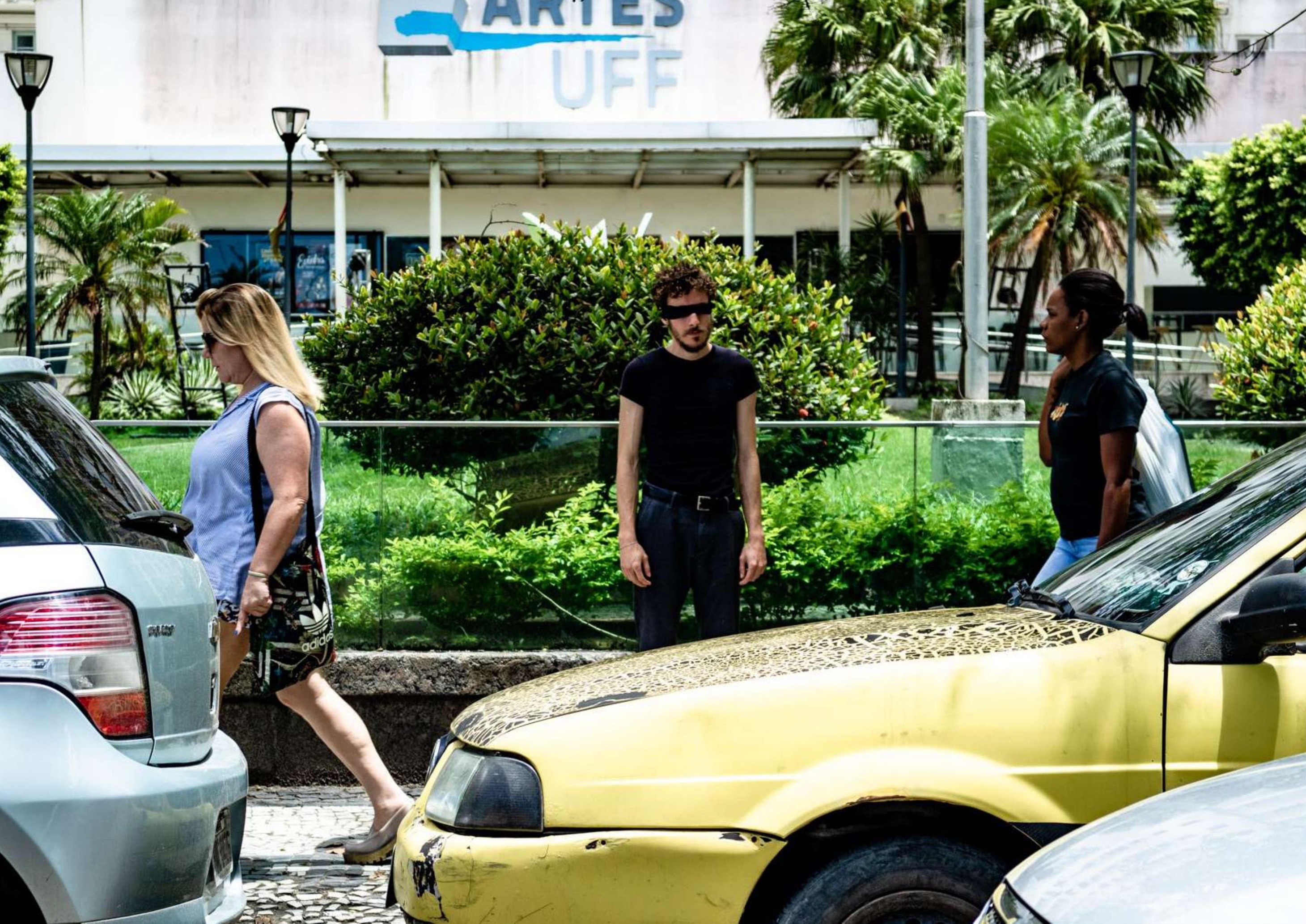




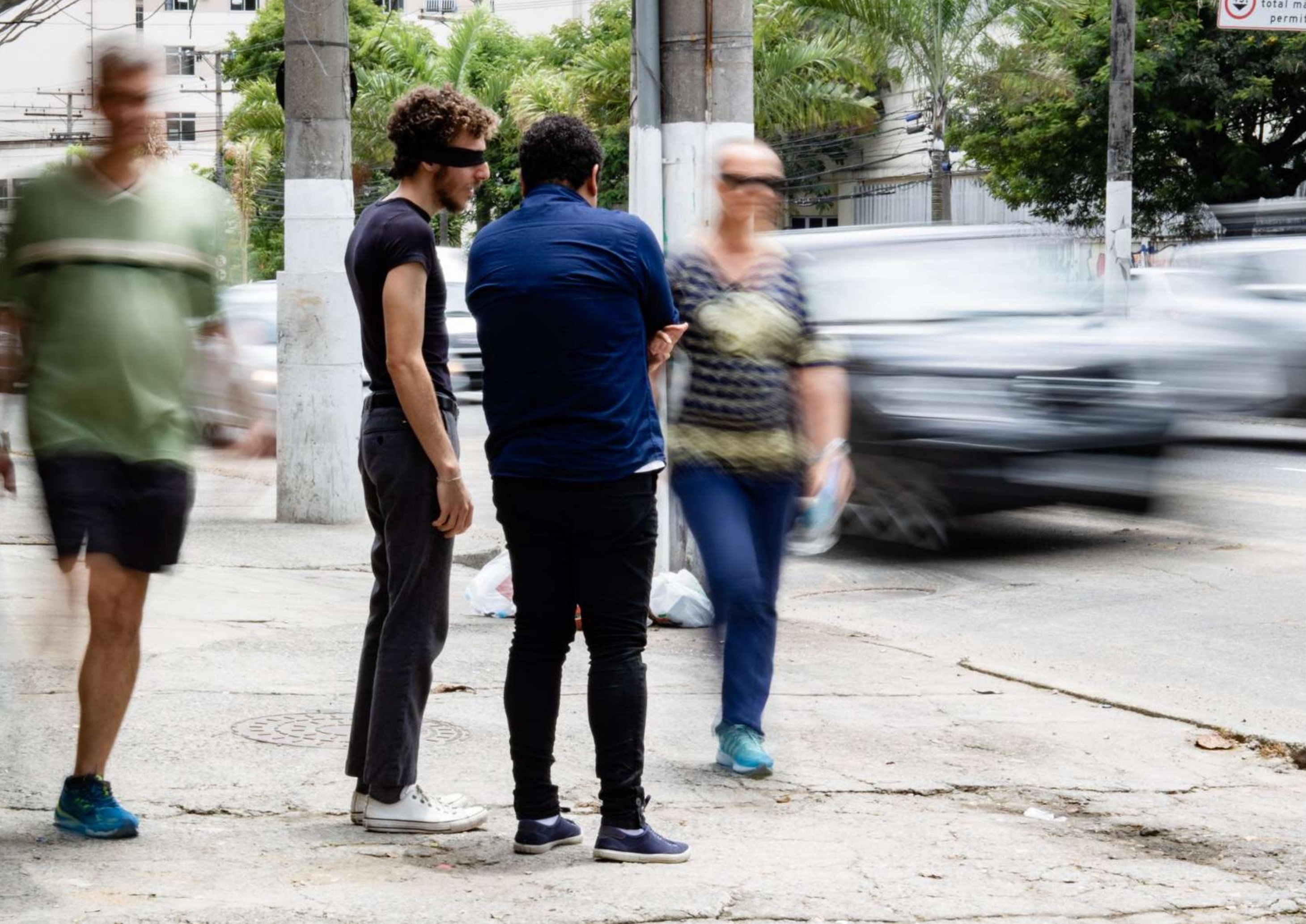




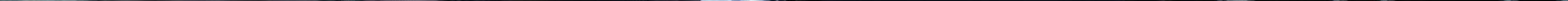




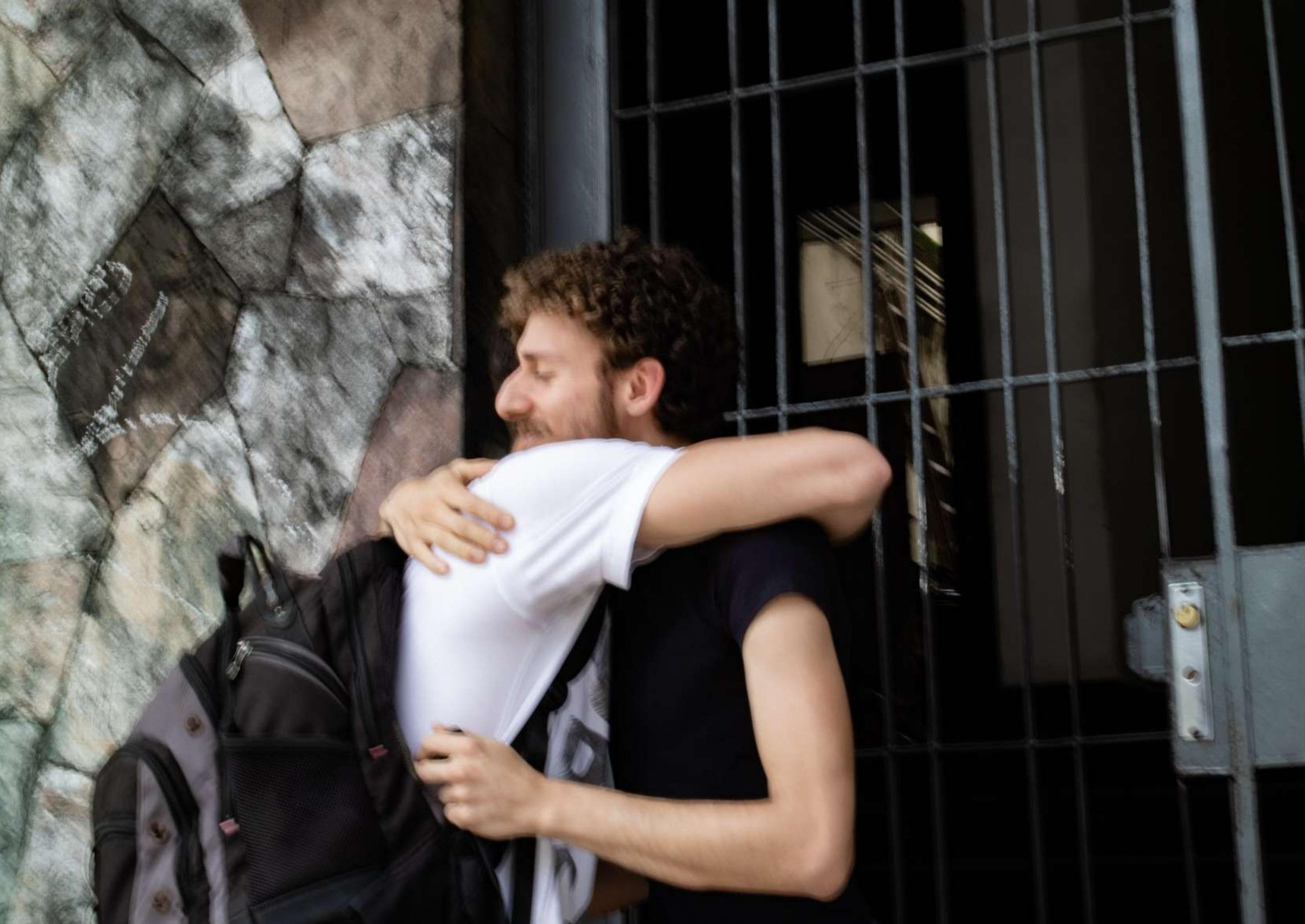




\section{Fotos: Ana Valvassori e Leo Farada}

Recebido: 27 de maio de 2019; aceito: 05 de março de 2020

Este é um artigo publicado em acesso aberto sob uma licença Creative Commons (cc)) Br 